\title{
REVISED Co-producing health care - pragmatic principles and an
}

\section{illustration [version 2; peer review: 2 approved]}

\author{
Axel Kaehne (D1) Lucy Bray², Edmund Horowicz ${ }^{1}$ \\ ${ }^{1}$ Medical School, Edge Hill University, Ormskirk, L39 4QP, United Kingdom \\ ${ }^{2}$ School of Nursing, Edge Hill University, Ormskirk, L39 4QP, United Kingdom
}

\author{
V2 First published: 26 Mar 2020, 2:10 \\ https://doi.org/10.35241/emeraldopenres.13475.1 \\ Latest published: 18 Jun 2020, 2:10 \\ https://doi.org/10.35241/emeraldopenres.13475.2
}

\begin{abstract}
Co-production has received increasing attention from managers and researchers in public services. In the health care sector, co-production has become a by-word for the meaningful engagement of patients yet there is still a lack of knowledge around what works when coproducing services. The paper sets out a set of pragmatic principles which may guide anyone embarking on co-producing health care services, and provides an illustration of a co-produced Young People's Health Research Group in England. We conclude by outlining some learning points which are useful when establishing co-production projects.
\end{abstract}

\section{Keywords}

co-production, health care, health research, public services, public engagement, participation

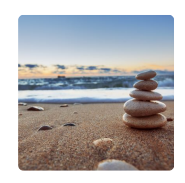

This article is included in the Healthier Lives gateway.

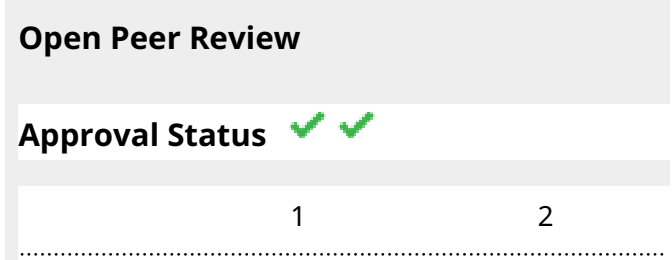

version 2

(revision)

18 Jun 2020

version 1

26 Mar 2020

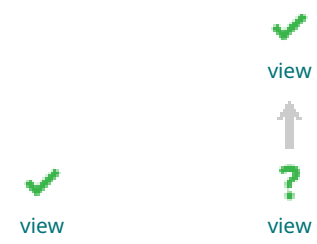

1. Racheal Smithson, Griffith University, Gold Coast, Australia

2. Kathy Boxall, Edith Cowan University, Bunbury, Australia

Adam Johnson, Edith Cowan University, Joondalup, Australia

Any reports and responses or comments on the article can be found at the end of the article.

Corresponding author: Axel Kaehne (axel.kaehne@edgehill.ac.uk)

Author roles: Kaehne A: Conceptualization, Methodology, Project Administration, Supervision, Writing - Original Draft Preparation, Writing - Review \& Editing; Bray L: Writing - Original Draft Preparation, Writing - Review \& Editing; Horowicz E: Writing - Original Draft Preparation, Writing - Review \& Editing

Competing interests: No competing interests were disclosed.

Grant information: The author(s) declared that no grants were involved in supporting this work.

Copyright: $\odot 2020$ Kaehne A et al. This is an open access article distributed under the terms of the Creative Commons Attribution License, which permits unrestricted use, distribution, and reproduction in any medium, provided the original work is properly cited.

How to cite this article: Kaehne A, Bray $L$ and Horowicz E. Co-producing health care - pragmatic principles and an illustration [version 2; peer review: 2 approved] Emerald Open Research 2020, 2:10 https://doi.org/10.35241/emeraldopenres.13475.2

First published: 26 Mar 2020, 2:10 https://doi.org/10.35241/emeraldopenres.13475.1 


\section{REVISED Amendments from Version 1}

Our thanks goes to the reviewers for their very useful comments for improvement. We have addressed their helpful comments by revising the text of the paper (with additions to What is coproduction, A set of pragmatic principles for co-production, and What it may lead to sections) and uploading our responses to reviewers.

Any further responses from the reviewers can be found at the end of the article

\section{Background}

The need to co-produce health care services has been debated for decades (Batalden et al., 2016; Bovaird, 2007; Oliver et al., 2019). The most recent NHS Five Year Forward states that health organisations 'need to engage with communities and citizens in new ways, involving them directly in decisions about the future of health and care services.' (Public Health England - Trust Development Authority. NHS England Care Quality Commission Health Education England Monitor, 2014, p.13).

Co-production in health is thought to contribute to improved patient outcomes, more efficient use of resources, and is linked to the wider notion of effective citizenship through participatory practice in democratic societies (Jung, 2010; Ocloo \& Matthews, 2016; Realpe \& Wallace, 2010).

Despite increased attention on co-production in health care, there is little consensus on how to meaningfully engage patients and service users effectively when re-designing local and national services. Methods and practices vary and are often based on local expertise and initiatives. Observers note that the field of co-production is populated with aspirational statements and tokenistic actions (Hudson, 2014; Kaehne \& Taylor, 2016; Oliver et al., 2019).

Our paper will draw on the existing literature to give an overview of the current understanding of co-production in health care. We will set out a pragmatic set of principles that should guide organisations when co-producing their services. To support these principles we will provide an illustration of co-producing health care research in the North West of England.

In this paper we will use the terms 'patient', 'service user' or 'client' interchangeably. We are aware of the considerable discussion about the different implications of these terms. However, this paper is not concerned with the role and status of users of health care in economic terms. Using the terms interchangeably simply reflects our desire to discuss the issue of co-production in health research in a comprehensive way, regardless of their different economic status or role.

\section{What is co-production?}

Co-production has been practiced under different guises for many years, with some practices being better than others. The Health Foundation provides a working definition of co-production as an engagement that requires users to be experts in their own circumstances and capable of making decisions, while professionals move from being fixers to facilitators. The authors emphasise that, to be truly transformative, co-production requires a relocation of power towards service users (Realpe \& Wallace, 2010).

In the literature, there is often a distinction made between various ways of working representing different levels of engagement, ranging from activities aimed at users, activities aimed for users, to activities that are aimed to meaningfully include users. Arnstein's ladder of participation is the original conceptualisation in this field, setting out varying categories of engaging recipients of services (Arnstein, 1969; Gibson et al., 2012; Hudson, 2014). There are various adaptions of her framework which, in its most sophisticated form, may include 7 different types of participation, within 3 broader domains (Figure 1) (Slay \& Stephens, 2013).

The need for a shift in co-production of health services from the lower rungs of the participation ladder has been recognised by key organisations e.g. the World Health Organisation (WHO) in 2016 who stated that a fundamental paradigm shift was needed to put people and communities at the centre of designing and shaping health care services

Most health care organisations consult with patients and service users about their needs, often in the form of patient satisfaction surveys. Whilst consulting patients allows health care organisations to obtain data on patient views and patient needs, consultations do not claim to involve patients in service design (Horrocks et al., 2010; Tuffrey-Wijne \& Butler, 2010; Van Damme \& Brans, 2012) and often allow patients and service users only to comment or rate according to pre-defined criteria.

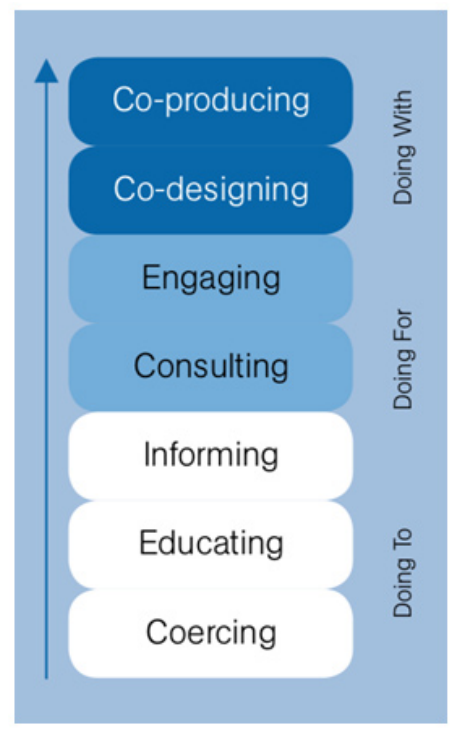

Figure 1. Ladder of Participation. Reproduced from Slay \& Stephens (2013) under the terms of the Creative Commons AttributionNonCommercial-NoDerivs 3.0 Unported (CC BY-NC-ND 3.0). 
If patient consultation is located on the lower steps of Arnstein's ladder of participation, patient engagement represents one of the higher rungs of the ladder. Ocloo and Matthews chart the path of progression from tokenistic to genuine engagement of patients (Ocloo \& Matthews, 2016). Engaging with, and involving, patients can take many forms and may include ad hoc conversations with patients or more systematic attempts to draw service users into discussions about re-structuring or re-designing services (Boxall \& Ralph, 2011; Hudson, 2014; Purvis et al., 2012; Walmsley \& Johnson, 2003). A key difference to patient consultation is the ambition to involve patients to allow them to take part in service meetings and forae at which decisions are taken relevant to them. Access to, and involvement in these discussions and decisions are often controlled and organised by those working for health care organisations, begging the question of how deep and meaningful this involvement is. Co-production is seen as being the ultimate step in patient participation in the re-design of services. Research has identified specific conditions which make for effective co-production whilst pointing to the largely tokenistic nature of some patient involvement in the NHS (Batalden et al., 2016). The Social Care Institute for Excellence in the UK defines these conditions as notions of equality, diversity, accessibility and reciprocity (SCIE, 2015).

\section{Challenges of creating meaningful co-production}

There are several issues that compound the difficulties of implementing genuine co-production of services. The first challenge for co-producing services is that health care organisations operate and institute two different logics of service delivery, one for patients and service users and one for the organisation and staff (Kaehne \& Catherall, 2013). All organisations serving the public are structured by management principles prioritising effectiveness, efficiency and outcomes. Whilst this is to the benefit of patients and service users overall, patients approach and articulate their demands towards health care often through the lens of individual needs, which are conventionally perceived as underpinning principles of patient centred care and holistic service delivery (Lwembe et al., 2017).

The epistemic link between the activity of co-producing services with patients and service users and service outcomes for the broader service population is often not clear, which is a result of the different logics of care and approaches to 'need' that come to be applied by patients and organisations. With some notable exceptions, patients may frequently express individual needs, whereas organisations have obligations towards all potential users of their services. This aspect is often couched in terms of representativeness of patient involvement, yet the literature also clearly articulates the epistemic boundaries of individual patient experiences (Kaehne et al., 2018; Kaehne \& Catherall, 2013). Whilst it is important that individual voices are heard, extrapolating from these voices to wider population needs may be perceived as problematic when patient needs are framed by the concept of person centred care.

The second challenge for co-production emerges from the disparities between intent and practice. Ambitious statements about co-producing services vie for attention with some guidance on how to do this effectively such as the one formulated by the Coalition for Collaborative Care. There is little robust evidence at present of what constitutes good and effective co-production and how to measure its impact (Batalden et al., 2016). For genuine collaboration to flourish, services need to come to terms with the idea of co-production as a non-linear, emergent, transparent and dynamic process (Daviter, 2017; Kaehne, 2016), which needs an investment in time. This runs counter to well established management tenets of control and direction by professional expertise. There are many reports of successful co-production, but fewer accounts of when collaborations have not flourished and engagement has been constrained by rigid services, organisations and processes.

In light of these challenges, service managers may resign themselves to conducting activities more aligned to consultation and engagement, leaving them in control of the collection and interpretation of patient views. Creating genuinely co-produced services, however, is possible when health care organisations are aware of a basic set of principles that circumscribe and underpin meaningful co-production, develop a flexible framework for implementing co-production practices and assess and review frequently their impact.

\section{A set of pragmatic principles for co-production}

We have articulated previously some key principles that should guide managers when planning co-production activities (Kaehne et al. 2018; Kaehne \& Taylor, 2016). These principles reflect basic assumptions articulated in the management literature about health care services in times of change (Braithwaite \& Mannion, 2011; Chambers, 2011; Fitzgerald, 2017) which can help us understand the impetus and direction of travel of co-production.

The principles we articulated are meant to furnish foundational tenets, informing the approach of managers to co-production in general. There is of course a difference of purpose between coproducing health service delivery and health service research. Both fields however are types of engagement with individuals who are traditionally marked out by their liminality or marginality. The principles we provide below therefore have applicability in both co-producing service delivery and co-producing health research. This does not affect their specificity when it comes to operationalise specific objectives, aims and processes in different contexts.

Firstly, managers should reflect on the nature of their service as a public service with an attendant set of values. Conceptualising their work as something contributing to a wider public good may focus their attention on the active role of patient and service users in contrast to the conventionally passive role of patients and service users as recipients of a service. Once user preferences are seen as an intrinsic component of effective service delivery, active participation of patients and service users can be perceived as an integral part of service design. Whilst this point may appear plausible to us and reverberates through most policy documents, Lipsky and others have long 
argued that there are powerful restraints on staff being able to act in this logical manner (Keulemans \& Van de Walle, 2020; Lipsky, 1980). As they point out, in the context of a universally funded public sector, staff are obligated to organisations in terms of accountability, not to the users of services. Meaningful co-production may thus require a seismic attitudinal shift amongst staff and managers in order for them to privilege, and be sensitive to, patient perspectives.

Secondly, involving patients in a meaningful way entails creativity, an openended-ness, and should be seen as an iterative, dialogical practice of engaging individuals of different status, experience and epistemic boundaries, rather than a linear, ad hoc, delimited process with peers.

This leads to the third principle defining co-production. Patients and service users bring expertise to the table that is bounded, individualised and specific to their health care needs. Managers drawing on their participation for the purpose of re-designing care services need to be aware that they are engaging in an exercise of sense making, interpreting individual patient and service user contributions to co-design services from individual perspectives. This may easily lead to a de-legitimisation of patient voices, when managers associate their preferences with wider population needs.

These three general principles only demarcate some basic assumptions that underpin the meaningful co-production of patients and service users in service re-design. They underdetermine the actual practice of co-production but set parameters for patient and service user engagement.

There are various tools and frameworks in the public domain which may be helpful when implementing co-production. From the plethora of frameworks available we found that the NHS England 5 Values and 7 Steps model works well in most contexts. It meets the requirements of organisational commitment, sensitivity to patient and service user support needs when participating in co-production, and iteration through regular review of progress. What it cannot give however is to reflect the level of fine tuning necessary in particular circumstances for any given co-production project. Just like any large scale improvement programme in health care, co-producing services remains an endeavor calling for craft rather than science (Dickinson, 2014; Ferlie et al., 2016), and learning may best be done through illustration. We share in the next section our experiences of a co-production project enabling young people to develop skills to challenge and guide researchers to improve their understanding of the needs of this population within health care.

\section{An Illustration: Establishing a Young Peoples' Health Research Group}

In this section we document our own experiences of having established a young peoples' health research group. In doing so we highlight that meaningful involvement with young people can best be facilitated by a long-term commitment to establishing positive authentic relationships underpinned by mutual learning. In using the term authentic we mean that a genuine and shared mutual aim to generate knowledge develops through an understanding of each other's different perspectives.

As health researchers we have, on many occasions, consulted with established children and young peoples' health forums within hospital services in order to shape our research designs and approaches. However, whilst these groups offer a vital contribution to children and young peoples' health research, one consideration is that these established groups can often be mostly constituted by children who have a long-term relationship with an organisation, often as a result of care provided for a particular condition or long-term health need. Furthermore, these groups are often professionally led and thus reflect a model more in line with engagement activities as outlined earlier. In contrast, we were keen to engage and consult with children and young people who may have less experience of health care organisations and health conditions. In doing so it was important to move our practice away from consultation and engagement, towards a model of co-production. Our rationale was that by doing so we would develop more authentic relationships and therefore established a health research group on the basis of co-production principles.

\section{How we did it}

We established connections with a local high school, through a teacher who recognised the potential for the link to provide opportunities for her students. She invited interested students to come along to meet us. Our first session involved introductions and activities to provide an overview of what research was and the important role of consultation (PPIE) within health research. The young people were engaged and interested and were keen to 'sign up' to the endeavour. We were committed to equip these young people with appropriate skills and research training before we asked them to become involved in acting as advisors and being involved in shaping research. However, from the outset it became apparent that we would need to build relationships with members of the group to support the development of confidence, both within the group and for individuals.

The group is held within the school environment as an extracurricular activity and has been attended by $10-15$ young people aged 11-15 years on each occasion. The group meets once every school term. Over the course of the school year, we used group activities to cover topics including research questions, qualitative and quantitative designs, choosing different data collection methods and different ways to share research findings. In designing these activities, we asked the group to relate their learning to issues that affected them, such as accessing technology. Following each of the research training activities, we asked the young people to apply their learning to a particular project or task that we were involved with and that would benefit from young peoples' input and review. The young people have advised on a range of health-related research including; the design of a proposed pragmatic trial to evaluate a digital intervention for children coming to hospital, the development of animation resources based on research data from 
children and young about what to expect when coming to hospital and the development of creative data collection methods.

The sessions have been facilitated by two academics (LB and $\mathrm{EH}$ ), who are experienced in working with children and young people. All of the group sessions use creative activities, which encouraged movement, interaction and young people to share their views both verbally and in writing. The design of the activities and consultation are mindful of young people having different preferences for how they engage and share their views. We have noticed over time how an atmosphere of trust and openness has developed, with the young people sharing their views willingly and with confidence and increasingly challenging our ideas and plans. We have learnt through these experiences 'what works well' and how the young people engage and respond in different ways to the activities. Our engagement has begun to shift from engagement to young people defining what matters to them and identifying topics of importance to them.

\section{What it may lead to}

After a year we held a session to review and evaluate the group with the young people and we used a tree of growth to explore what had been achieved within the last year. The young people reported that being involved in the group had helped them 'learn about research', 'feel part of a research team', 'feel more confident', and they felt a sense of achievement in having helped 'make children's research better' by 'having a voice' in how it was designed and shared. The review raised that the young people felt it was important to formalise the group by agreeing the aims and aspirations for our ongoing engagement and creating a name and identity. We held a prioritisation session to name the group following a collection of nominations, with the young people voting for 'Young Peoples' Health Research Group' and from this we have co-created terms of reference for the group.

Whilst the original aim was to develop meaningful research engagement with young people, we have realised that in doing so there is an opportunity to positively support the development and achievements of a group of young people. We are keen to develop the group further by supporting the young people to lead on their own projects. Establishing this group has not been easy but the rewards have exceeded any of our hopes and expectations. So far, the groups' feedback and views resulted in valuable changes to the creation of dissemination materials (animations) from one project and to the key outcomes and data collection methods proposed in a research funding application. We also faced some challenges along the way. We found it difficult to ensure that the school population (age range and sex) was represented within the constitution of the group. To date, group membership remains predominantly female, and this may be due to the initial alignment with an existing confidence improvement group within the school. We finish with some learning points.

\section{Learning points}

1. Developing meaningful and valued relationships requires patience, time and openness.

2. Investing in developing relationships promotes honest and open working and fosters co-production.

3. Working creatively and flexibly is important to ensure that the work of the group addresses the interests and needs of the group members and not just the agendas of the researchers/professionals.

4. Whilst researchers, professionals and group members may have different roles and expertise, there must be a common agreed aim to embrace these differences and develop shared knowledge.

5. Celebrate the development and achievements of the group and group members.

\section{Conclusion}

This paper has outlined some of the challenges of engaging in the co-production of health care. We have articulated a set of pragmatic principles that should guide managers when embarking on co-producing their services and provided an illustration from health care research about how consultation with young people can develop into a co-production effort. Whilst the barriers to genuinely co-producing care are considerable, the effort should match our ambition as expressed in current NHS policy to involve patients and service users in creating services that affect them.

\section{Ethical considerations}

The Young People's Health Research involved working with young people as part of Patient and Public Involvement and Engagement activity. The HRA and INVOLVE joint statement highlights that 'you do not need to apply for ethical approval to involve the public in the planning or the design stage of research' (https://www.invo.org.uk/wp-content/uploads/2016/05/HRAINVOLVE-updated-statement-2016.pdf, page 2). However, our ways of working with the group are underpinned by ethical practices and behaviours in line with ethically conscious standards for working with public relating to health and social care research. The young people who attended the Young Peoples' Health Research Group had permission to be part of the endeavour from their parent or carer.

\section{Data availability \\ Underlying data}

All data underlying the results are available as part of the article and no additional source data are required.

\section{Acknowledgement}

We thank all the members of the Young Peoples' Health Research Group and their fantastic Pastoral Mentor, Mrs H.M. Coggins at Ormskirk School in Lancashire. 
Arnstein SR: A Ladder Of Citizen Participation. J Am I Planners. 1969; 35(4): 216-224.

Publisher Full Text

Batalden M, Batalden P, Margolis $\mathrm{P}$, et al:: Coproduction of healthcare service. BMJ Qual Saf. 2016; 25(7): 509-517.

PubMed Abstract | Publisher Full Text | Free Full Text

Bovaird T: Beyond Engagement and Participation: User and Community Coproduction of Public Services. Public Admin Rev. 2007; 67(5): 846-860. Publisher Full Text

Boxall K, Ralph S: Research ethics committees and the benefits of involving people with profound and multiple learning disabilities in research. $\mathrm{Br} J$ Learn Disabil. 2011; 39(3): 173-180.

Publisher Full Tex

Braithwaite J, Mannion R: Managing Change. in Walshe, K. and Smith, J. (eds) Healthcare Management. 2nd edn. Maidenhead: McGrawHill, 2011; 427-451.

Chambers N: Leadership and Governance. in Walshe, K. and Smith, J. (eds) Healthcare Management. 2nd edn. Maidenhead: McGrawHill, 2011; 377-400. Reference Source

Daviter F: Policy analysis in the face of complexity: What kind of knowledge to tackle wicked problems? Public Policy Admin. 2017; 34(1): 62-83.

Publisher Full Text

Dickinson H: Making a reality of integration: less science, more craft and graft. J Integr Care. 2014; 22(5/6): 189-196.

Publisher Full Tex

Ferlie E, Montgomery K, Pedersen AR: The Oxford Handbook of Health Care Management. Oxford: Oxford University Press, 2016.

Publisher Full Text

Fitzgerald L: Contextualising Organisational Change. The Case of Health Care. in Fitzgerald, L. and McDermott, A. (eds) Challenging Perspectives on Organisational Change in Health Care. Abingdon: Routledge, Taylor \& Francis Group, 2017; 67-84.

Gibson A, Britten N, Lynch J: Theoretical directions for an emancipatory concept of patient and public involvement. Health (London). 2012; 16(5): $531-547$.

PubMed Abstract | Publisher Full Text

Horrocks J, Lyons C, Hopley P: Does strategic involvement of mental health service users and carers in the planning, design and commissioning of mental health services lead to better outcomes? Int J Consum Stud. 2010; 34(5): $562-569$.

Publisher Full Text

Hudson B: Public and Patient Engagement in Commissioning in the English NHS: An idea whose time has come? Public Manag Rev. 2014: 17(1): 1-16. Publisher Full Text

Jung T: Citizens, Co-producers, Customers, Clients, Captives? A critical review of consumerism and public services. Public Management Review. 2010; 12(3): 439-446.

Publisher Full Text

Kaehne A: Complexity in programme evaluations and integration studies: What can it tell us? J Integr Care. 2016; 24(5-6): 313-320.

Publisher Full Text

Kaehne A, Beacham A, Feather $\mathrm{J}$ : Co-production in integrated health and social care programmes: a pragmatic model. J Integr Care. 2018; 26(1): 87-96. Publisher Full Text
Kaehne A, Catherall C. User involvement in service integration and carers' views of co-locating children's services. J Health Organ Manag. 2013; 27(5): $601-617$

PubMed Abstract | Publisher Full Text

Kaehne A, Taylor H: Do public consultations work? The case of the Social Services and Well-being (Wales) Bill. Public Policy Admin. 2016; 31(1): 80-99. Publisher Full Text

Keulemans S, Van de Walle S: Understanding street-level bureaucrats' attitude towards clients: Towards a measurement instrument. Public Policy Adm. 2020; 35(1): 847-113.

Publisher Full Text

Lipsky M: Street-Level Bureaucracy. The Dilemmas of the Individual in Public

Services. New York: Russell Sage Foundation, 1980.

Reference Source

Lwembe S, Green SA, Chigwende J, et al:: Co-production as an approach to developing stakeholder partnerships to reduce mental health inequalities: an evaluation of a pilot service. Prim Health Care Res Dev. 2017; 18(1): 14-23. PubMed Abstract | Publisher Full Text

Ocloo J, Matthews R: From tokenism to empowerment: progressing patient and public involvement in healthcare improvement. BMJ Qual Saf. 2016; 25(8): $626-632$

PubMed Abstract | Publisher Full Text | Free Full Text

Oliver K, Kothari A, Mays N: The dark side of coproduction: do the costs outweigh the benefits for health research? Health Res Policy Syst. 2019; 17(1): 33

PubMed Abstract | Publisher Full Text

Public Health England - Trust Development Authority. NHS England Care Quality Commission Health Education England Monitor: Five Year Forward View. London, 2014.

Reference Source

Purvis A, Small L, Lowrey J, et al:: Project SEARCH Evaluation: Final Report. London: Centre for Economic and Social Inclusion, 2012.

Reference Source

Realpe A, Wallace LM: What is co-production? The Health Foundation. London. 2010.

Reference Source

SCIE: Co-production in social care: what it is and how to do it. London. 2015. Reference Source

Slay J, Stephens L: Co-production in mental health: A literature review. London: New Economics Foundation, 2013.

Reference Source

Tuffrey-Wijne I, Butler G: Co-researching with people with learning disabilities: an experience of involvement in qualitative data analysis. Health Expect. 2010; 13: $174-184$.

PubMed Abstract | Publisher Full Text | Free Full Text

Van Damme J, Brans M: Managing Public Consultation: A Conceptua framework and empirical findings from Belgian Case Studies. Public Admin 2012; 90(4): 1047-1066.

Publisher Full Text

Walmsley J, Johnson K: Inclusive research with people with learning disabilities. Past, present and futures. London and Philadelphia: Jessica Kingsley, 2003.

Reference Source 


\section{Open Peer Review}

\section{Current Peer Review Status:}

\section{Version 2}

Reviewer Report 15 July 2020

https://doi.org/10.21956/emeraldopenres.14877.r26909

(C) 2020 Boxall $\mathbf{K}$ et al. This is an open access peer review report distributed under the terms of the Creative Commons Attribution License, which permits unrestricted use, distribution, and reproduction in any medium, provided the original work is properly cited.

\section{Kathy Boxall}

School of Arts and Humanities, Edith Cowan University, Bunbury, WA, Australia

Adam Johnson

Edith Cowan University, Joondalup, Australia

'The need for a shift in co-production of health services from the lower rungs of the participation ladder has been recognised by key organisations e.g. the World Health Organisation (WHO) in 2016'- reference needed for the WHO article.

'the important role of consultation (PPIE) within health research' - this acronym is not defined.

Competing Interests: No competing interests were disclosed.

Reviewer Expertise: Participatory action research, disability, social inclusion, local government (Johnson). Service user involvement, participatory methodologies, user-led and user-controlled research (Boxall)

We confirm that we have read this submission and believe that we have an appropriate level of expertise to confirm that it is of an acceptable scientific standard.

\section{Version 1}

Reviewer Report 16 April 2020

https://doi.org/10.21956/emeraldopenres.14545.r26698 
(C) 2020 Boxall $\mathbf{K}$ et al. This is an open access peer review report distributed under the terms of the Creative Commons Attribution License, which permits unrestricted use, distribution, and reproduction in any medium, provided the original work is properly cited.

\section{Kathy Boxall}

School of Arts and Humanities, Edith Cowan University, Bunbury, WA, Australia

\section{Adam Johnson}

Edith Cowan University, Joondalup, Australia

Thank you for the opportunity to review the article by Kaehne, Bray \& Horowicz (2020), which identifies an important area in need of research - how to practically implement co-production in health care research in order to improve service quality. The article begins with a helpful review of related literature and goes on to identify some pragmatic principles for co-production based on the research experience of the authors. It also offers an illustrative example from which some 'learning points' are extrapolated for those wanting to establish co-production projects.

We felt that the article could be improved in a few areas, as outlined below.

Some statements could be better supported with brief examples - for example: "Research has identified specific conditions which make for effective co-production whilst pointing to the largely tokenistic nature of some patient involvement in the NHS" (Batalden et al., 2016). It would have been helpful if these conditions could have been listed.

Other statements would have benefitted from supporting references - for example, "These principles reflect basic assumptions articulated in the management literature about health care services which can help us understand the impetus and direction of travel of coproduction".

Overall, we found the illustration helpful and the obvious commitment by the researchers to equipping and mentoring young people to meaningfully participate in a process of research was clearly apparent - it would however have been helpful to know how often the researchers and young people met during the one-year period. It would also have been helpful to have had clearer explanation of the methodology employed. For example, the statement, "All of the group sessions use creative activities, which encouraged movement, interaction and young people to share their views both verbally and in writing" would have benefitted from further explanation or examples. Likewise, some reasons why "Establishing this group has not been easy" could have been provided if method is intended as a focus of this paper.

We also wondered about the apparent lack of ethics clearance for the researchers to work with the young people for a period of one year, which they explain as being unnecessary because, "The HRA and INVOLVE joint statement highlights that, "you do not need to apply for ethical approval to involve the public in the planning or the design stage of research". We feel there should be some discussion of the ethics of involving young people in the design stage of several different projects over an extended period. This is particularly so given there were a range of not insignificant outcomes, namely: "the design of a proposed pragmatic trial to evaluate a digital intervention for children coming to hospital, the development of animation resources based on research data from children and young about what to expect when coming to hospital and the development of creative data collection methods". There needs to be some explanation as to why the activities leading to these outcomes were not regarded as integral to the research endeavour. Discussion 
about the ethics of not requiring ethics clearance for the design stage of research could stimulate considerable debate in this important area.

Is the work clearly and accurately presented and does it cite the current literature? Yes

Is the study design appropriate and is the work technically sound? Partly

Are sufficient details of methods and analysis provided to allow replication by others? Partly

If applicable, is the statistical analysis and its interpretation appropriate? Not applicable

Are all the source data underlying the results available to ensure full reproducibility? No source data required

Are the conclusions drawn adequately supported by the results? Yes

Is the argument information presented in such a way that it can be understood by a nonacademic audience?

Yes

Does the piece present solutions to actual real world challenges?

Yes

Is real-world evidence provided to support any conclusions made?

Yes

Could any solutions being offered be effectively implemented in practice?

Yes

Competing Interests: No competing interests were disclosed.

Reviewer Expertise: Participatory action research, disability, social inclusion, local government (Johnson). Service user involvement, participatory methodologies, user-led and user-controlled research (Boxall).

We confirm that we have read this submission and believe that we have an appropriate level of expertise to confirm that it is of an acceptable scientific standard, however we have significant reservations, as outlined above.

Reviewer Report 09 April 2020

https://doi.org/10.21956/emeraldopenres.14545.r26697 
(c) 2020 Smithson R. This is an open access peer review report distributed under the terms of the Creative Commons Attribution License, which permits unrestricted use, distribution, and reproduction in any medium, provided the original work is properly cited.

\section{Racheal Smithson}

Gold Coast Health, Menzies Health Institute, Griffith University, Gold Coast, Qld, Australia

This paper provides an interesting overview of co-production in health care. Co-production is a concept of increasing prominence in health service delivery and research, and there is very little evidence-based and pragmatic information to further the field of knowledge or support its development. There were four points that I wanted to make, which the authors might wish to reflect on:

- The background makes the case for why co-production is important from a policy perspective (ie. The FYFV states that health organisations need to do this), however the paper has not explicitly made the case for why it is important - ie. what are the benefits and how will it add value to health service delivery or research?

The authors interchangeably use descriptors of "communities", "citizens", "patients", "service users" to describe the same (I believe?) cohort of people. I wonder if a consistent term could be used or whether the authors could more clearly describe how/why they are using these various descriptors.

There is a difference in purpose and process between co-production in health service delivery and health service research, however I feel the authors conflate these work areas. It could be worth defining the scope of the paper more narrowly, differentiating between the two work areas, or explaining why the same principles apply regardless of work area. Additionally, regarding co-production in health service delivery, there are lots of examples of co-delivery (eg. peer support workers), which the authors could draw upon.

The authors conclude with the impact of co-production on the co-producers themselves, however do not provide conclusions regarding the impact on the delivery model and/or research. Going back to my first dot point, the case has not been made for why this is important for advancing health service delivery or research.

Is the work clearly and accurately presented and does it cite the current literature? Yes

Is the study design appropriate and is the work technically sound? Yes

Are sufficient details of methods and analysis provided to allow replication by others? Yes

If applicable, is the statistical analysis and its interpretation appropriate? Not applicable

Are all the source data underlying the results available to ensure full reproducibility? 


\section{No source data required}

Are the conclusions drawn adequately supported by the results? Partly

Is the argument information presented in such a way that it can be understood by a nonacademic audience?

Partly

Does the piece present solutions to actual real world challenges?

Partly

Is real-world evidence provided to support any conclusions made?

Partly

Could any solutions being offered be effectively implemented in practice?

Partly

Competing Interests: No competing interests were disclosed.

Reviewer Expertise: Health service management, Organisational research

I confirm that I have read this submission and believe that I have an appropriate level of expertise to confirm that it is of an acceptable scientific standard.

\section{Comments on this article}

\section{Version 1}

Author Response 11 Jun 2020

Axel Kaehne, Edge Hill University, Ormskirk, United Kingdom

Response to reviewers

Many thanks for the useful and thoughtful comments and suggestions for change from both reviewers. We have accepted all recommendations for change and detailed our responses in red below.

Some statements could be better supported with brief examples - for example: "Research has identified specific conditions which make for effective co-production whilst pointing to the largely tokenistic nature of some patient involvement in the NHS" (Batalden et al., 2016). It would have been helpful if these conditions could have been listed.

We agree and added the relevant conditions on page 4 and added the appropriate reference. 
Other statements would have benefitted from supporting references - for example, "These principles reflect basic assumptions articulated in the management literature about health care services which can help us understand the impetus and direction of travel of co-production".

We agree and added relevant references at this point in the paper.

Overall, we found the illustration helpful and the obvious commitment by the researchers to equipping and mentoring young people to meaningfully participate in a process of research was clearly apparent it would however have been helpful to know how often the researchers and young people met during the one-year period. It would also have been helpful to have had clearer explanation of the methodology employed. For example, the statement, "All of the group sessions use creative activities, which encouraged movement, interaction and young people to share their views both verbally and in writing" would have benefitted from further explanation or examples. Likewise, some reasons why "Establishing this group has not been easy" could have been provided if method is intended as a focus of this paper.

\section{We agree and have added a further explication of the methods used in the sessions. We also added a sentence detailing how often the group met.}

We also wondered about the apparent lack of ethics clearance for the researchers to work with the young people for a period of one year, which they explain as being unnecessary because, "The HRA and INVOLVE joint statement highlights that, "you do not need to apply for ethical approval to involve the public in the planning or the design stage of research". We feel there should be some discussion of the ethics of involving young people in the design stage of several different projects over an extended period. This is particularly so given there were a range of not insignificant outcomes, namely: "the design of a proposed pragmatic trial to evaluate a digital intervention for children coming to hospital, the development of animation resources based on research data from children and young about what to expect when coming to hospital and the development of creative data collection methods". There needs to be some explanation as to why the activities leading to these outcomes were not regarded as integral to the research endeavour. Discussion about the ethics of not requiring ethics clearance for the design stage of research could stimulate considerable debate in this important area.

\section{We agree that this is an important topic for debate. However we feel that it is outside the remit of this paper and would divert attention from the important issue of co-production that we are exploring.}

The background makes the case for why co-production is important from a policy perspective (ie. The FYFV states that health organisations need to do this), however the paper has not explicitly made the case for why it is important - ie. what are the benefits and how will it add value to health service delivery or research?

We agree and have added this on page 1 including a relevant reference.

The authors interchangeably use descriptors of "communities", "citizens", "patients", "service users" to describe the same (I believe?) cohort of people. I wonder if a consistent term could be used or whether the authors could more clearly describe how/why they are using these various descriptors. 
We agree and added a sentence on page 2 explaining why we believe it may be useful to use these terms interchangeably in this context.

There is a difference in purpose and process between co-production in health service delivery and health service research, however I feel the authors conflate these work areas. It could be worth defining the scope of the paper more narrowly, differentiating between the two work areas, or explaining why the same principles apply regardless of work area. Additionally, regarding co-production in health service delivery, there are lots of examples of co-delivery (eg. peer support workers), which the authors could draw upon.

Many thanks for making this really important point. We agree there is a significant difference between the two areas. We added an explanatory note on page 5 to indicate why we believe it may be helpful to keep the scope of this paper inclusive and broad, rather than narrow it to one area or the other.

The authors conclude with the impact of co-production on the co-producers themselves, however do not provide conclusions regarding the impact on the delivery model and/or research. Going back to my first dot point, the case has not been made for why this is important for advancing health service delivery or research.

We agree and have, as stated above, included this on page 1. See above.

Competing Interests: No competing interests were disclosed. 